\title{
Guidelines for the Identification of the MandibularVitalStructures: Practical Clinical Applications of Anatomy and Radiological Examination Methods
}

\author{
Gintaras Juodzbalys ${ }^{1}$, Hom-Lay Wang² \\ ${ }^{1}$ Department of Oral and Maxillofacial Surgery, Kaunas University of Medicine, Lithuania \\ ${ }^{2}$ Department of Periodontics and Oral Medicine, University of Michigan, Ann Arbor Michigan, USA
}

\author{
Corresponding Author: \\ Gintaras Juodzbalys \\ Vainiku 12 \\ LT-46383, Kaunas \\ Lithuania \\ Phone: +37037297055 \\ Fax: +370 37323153 \\ E-mail: gintaras@,stilusoptimus.lt
}

\begin{abstract}
Objectives: The purpose of this article was to review the current available clinical techniques and to recommend the most appropriate imaging modalities for the identification of mandibular vital structures when planning for oral implants.

Material and Methods: The literature was selected through a search of PubMed, Embase and Cochrane electronic databases. The keywords used for search were mandibular canal, mandibular incisive canal, mental foramen, anterior loop of the mental nerve, radiography, dental implants. The search was restricted to English language articles, published from January 1976 to January 2010.

Results: In total 111 literature sources were obtained and reviewed. The peculiarities of the clinical anatomy of mandibular canal, mandibular incisive canal, mental foramen and anterior loop of mental nerve were discussed. Radiological diagnostic methods currently available for the identification of the mandibular vital structures when planning for oral implants were presented. Guidelines for the identification of the mandibular vital structures in dental implantology were made.

Conclusions: The proposed guideline provides clinicians a tool in proper identifying the important mandibular vital structures thus minimizing the potential complications during implant surgery.
\end{abstract}

Keywords: mandible; chin; alveolar nerve, inferior; anatomy, cross-sectional; radiography; dental implants.

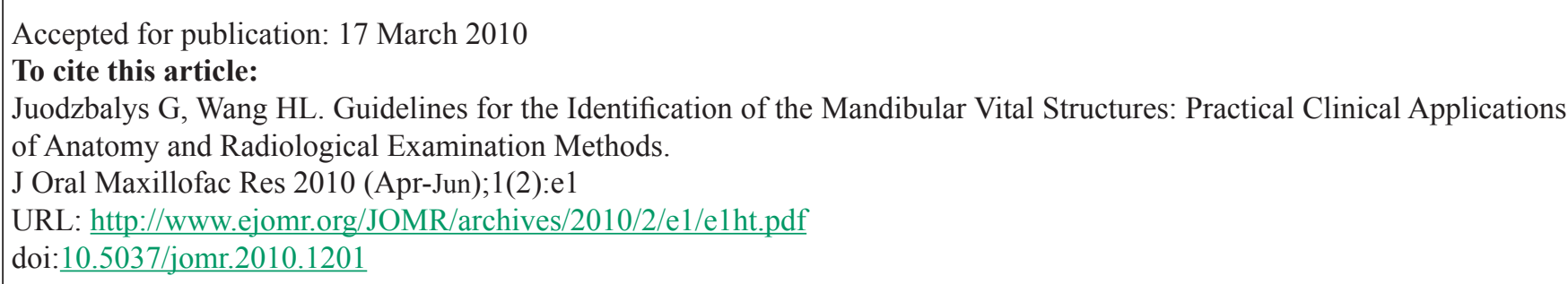




\section{INTRODUCTION}

Today, oral implants are routinely used in the oral rehabilitation. Yet, the frequent placement of oral implants has raised the number of neurosensory disturbances and haemorrhages, even in the anterior mandible, which was previously considered as a safe region without vital neurovascular bundles [1-4]. It is essential to obtain appropriate information about the mandible vital structures prior to implant placement []․ Knowledge of anatomy and their variations are essential to ensure precise surgical procedures to safeguard patient's vital structures [6-8]. Prior to commencement of implant surgery, careful and detailed planning is required to indentify mandibular vital structures as well as the shape and dimensions of the bone, so the implants can be properly orientated and placed. During the planning phase of treatment, the recipient bed is routinely assessed by visual examination and palpation, as well as the available medical imaging modalities. When adequate occlusoapical bone height is available for endosteal implants, the buccolingual width and angulation of the available bone are the most important criteria for implant selection and success [9]. Radiographic images provides the information about topography and location of the anatomical structures [10], and estimation of the quantity and quality of alveolar bone, which are essential in assessing the ideal position, number and dimensions of implants $[11,12]$. Many imaging options have been recommended for implant treatment planning, including intraoral radiography, conventional extraoral radiography, tomography, computed tomography (CT) [13-16], cone beam computed tomography (CBCT) [17-23]. However, neither buccolingual width nor angulation or assessment of the location of mandibular vital structures can be properly visualized on most traditional radiographs [9]. The purpose of this article was to review the current available clinical techniques and to recommend the most appropriate imaging modalities for the identification of mandibular vital structures when planning for oral implants.

\section{MATERIAL AND METHODS}

Literature was selected through a search of PubMed, Embase and Cochrane Central Register electronic databases. The keywordsused for search weremandibular canal, mandibular incisive canal, mental foramen, anterior loop of the mental nerve, radiography, dental implants. The search was restricted to English language articles, published from January 1976 to January 2010.
Additionally, a manual search in the major anatomy, dental implant, prosthetic and periodontal journals and books was performed. The included publications were clinical and human anatomy studies. To make it easier for readers, the peculiarities of the clinical anatomy of mandibular canal, mandibular incisive canal, mental foramen and anterior loop of mental nerve and radiologic diagnostic methods currently available for the identification of the mandibular vital structures when planning for oral implants were presented as two entities.

\section{Clinical and radiological evaluation of the mandibular anatomy for implantation}

Surgical dental implant installation requires understanding of associated anatomical structures. Planning should be done on three-dimensional edentulous jaw segment (EJS) pattern. This is because the EJS consists of alveolar and basal bone. In addition, EJS describes planned implant bed relation to present anatomical borders such as mandibular vital structures (Figure 1A) [24].

The vertical dimension of the planned implant site in mandible is determined by the distance between crestal ridge of the alveolar process and mandibular vital

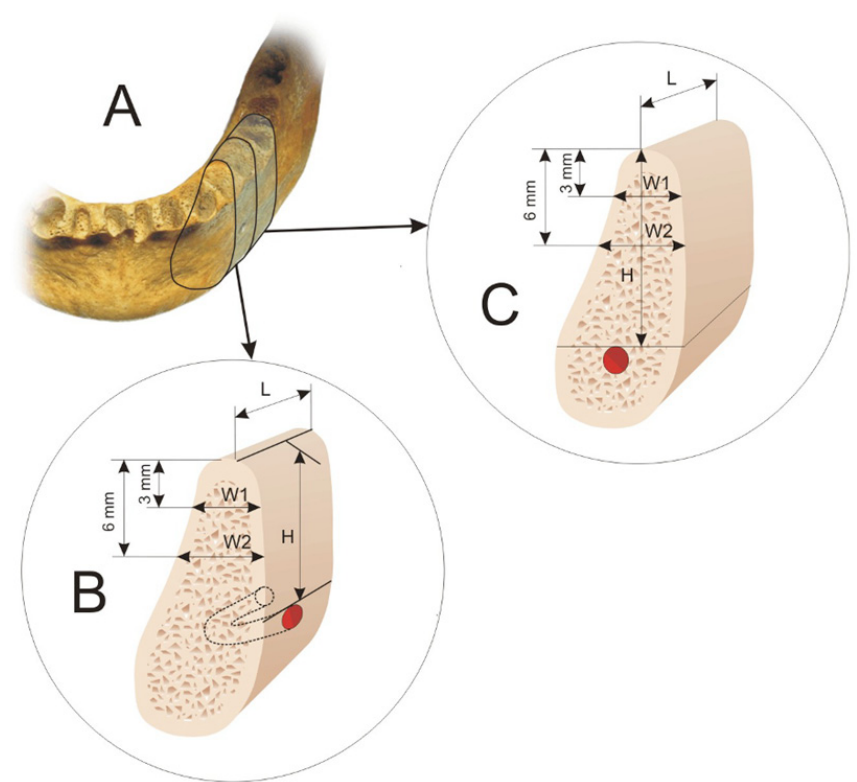

Figure 1. $A=$ mandible is divided into edentulous jaw segments that consists of alveolar and basal bone for planned implant bed.

$\mathrm{B}=$ the vertical dimension $(\mathrm{H})$ of the planned implant is determined by the distance between the alveolar ridge crest and mental foramen. $\mathrm{C}=$ the vertical dimension $(\mathrm{H})$ of the planned implant is determined by the distance between the alveolar crestal ridge and mandibular canal. The horizontal EJS dimensions: length (L) in all cases is determined by the distance between neighbouring teeth or implants and width $(\mathrm{W})$ is determined by the alveolar process width measured at the level of $3 \mathrm{~mm}$ (W1) and $6 \mathrm{~mm}$ (W2) from the crest of alveolar ridge. 

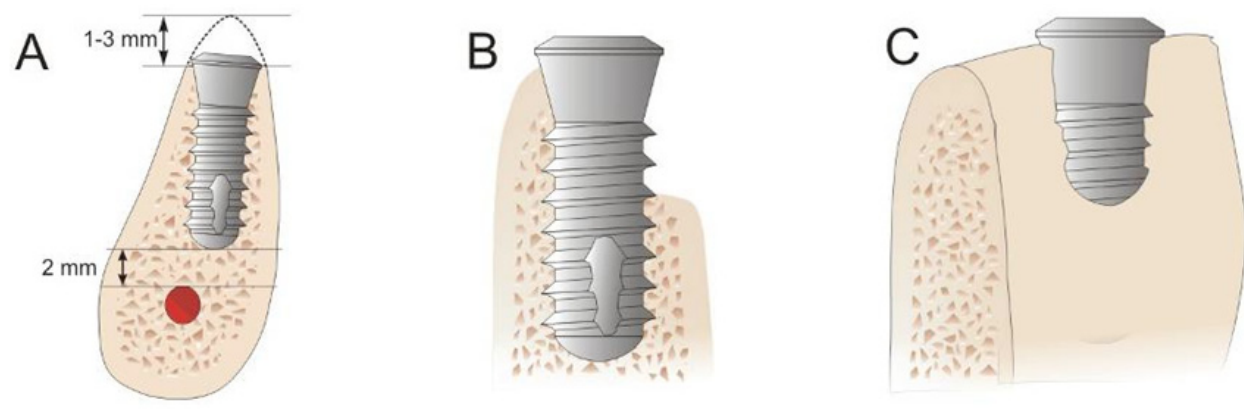

Figure 2. A = Thin crestal ridge was reduced to create wide recipient bed for planned implant installation. In such cases, the heights of EJS would have been shortened by 1 to $3 \mathrm{~mm}$ at least. $\mathrm{B}$ and $\mathrm{C}=$ another implant treatment option: crestal ridge preservation and dental implant surgical placement with subsequent alveolar process augmentation.

structures (EJS height) such as mental foramen (MF) (Figure $1 \mathrm{~B}$ ), mandibular canal (MC) (Figure $1 \mathrm{C}$ ), mandibular incisive canal (MIC), anterior loop (AL) of mental nerve. The horizontal dimensions are determined by the distance between neighbouring teeth or implants (EJS length) and width of alveolar process (EJS width) (Figure $1 \mathrm{~B}$ and $\mathrm{C}$ ).

Consequently, it should be done clinically and radiologically by identifying and depicting mandibular anatomical landmarks and position of important vital structures, when planning for dental implant operation.

\section{Peculiarities of mandibular canal (MC) clinical anatomy}

$\mathrm{MC}$ is one of the most important anatomical structures in mandible, because it carries inferior alveolar neurovascular bundle: inferior alveolar nerve (IAN), inferior alveolar artery, vein, and lymphatic vessels [25]. Clinicians should be aware of the variation in course of the $\mathrm{MC}$ as it runs through the jaw, because the MC may present in different anatomical configurations in vertical plane. For example, the canal may run lower when it proceeds anteriorly, or may have sharp decline, or drape downward in catenary's fashion [26]. Furthermore, Nortje et al. [27], on the panoramic radiographs, showed that the vertical MC position can be divided into four categories: 1) high MC (within $2 \mathrm{~mm}$ of the apices of the first and second molars), 2) intermediate MC, 3) low $\mathrm{MC}$, and 4) other variations - these includes duplication or division of the canal, apparent partial or complete absence of the canal or lack of symmetry. Otherwise, it should be recognized that the mean vertical distance between crestal ridge of the alveolar process and MC or MF reported in different classifications may not apply to any particular patient because of the different degree of alveolar bone atrophy. Moreover, because the crest of alveolar process is often thin, it is necessary to reduce it, so it can have wider base for the planned implant installation. In such cases, the heights of EJS would have been shortened by 1 to $3 \mathrm{~mm}$ at least; this reduction had to be considered when calculating the available bone height [24] (Figure 2 A). Clinicians should take care of the thin crestal bone smoothing and drill countersinking without losing the support of crestal cortical bone. Another implant treatment option is crestal ridge preservation by performing alveolar ridge augmentation (Figure $2 \mathrm{~B}$ and $\mathrm{C}$ ).

Furthermore, the ridge may appear to have adequate vertical dimension for an implant in panoramic radiograph, but the reality is often different (Figure 3).

It was reported that $\mathrm{MC}$ might have different anatomic configurations in the horizontal plane. Usually the $\mathrm{MC}$ crosses from the lingual to the buccal side of the mandible and in most cases the midway between the buccal and lingual cortical plates of bone is by the first molar [28-30]. Age and race were statistically associated with $\mathrm{MC}$ position relate to the mandibular buccal cortical bone $(\mathrm{P}<0.05)$.

Older patients and Caucasian patients, on average, have

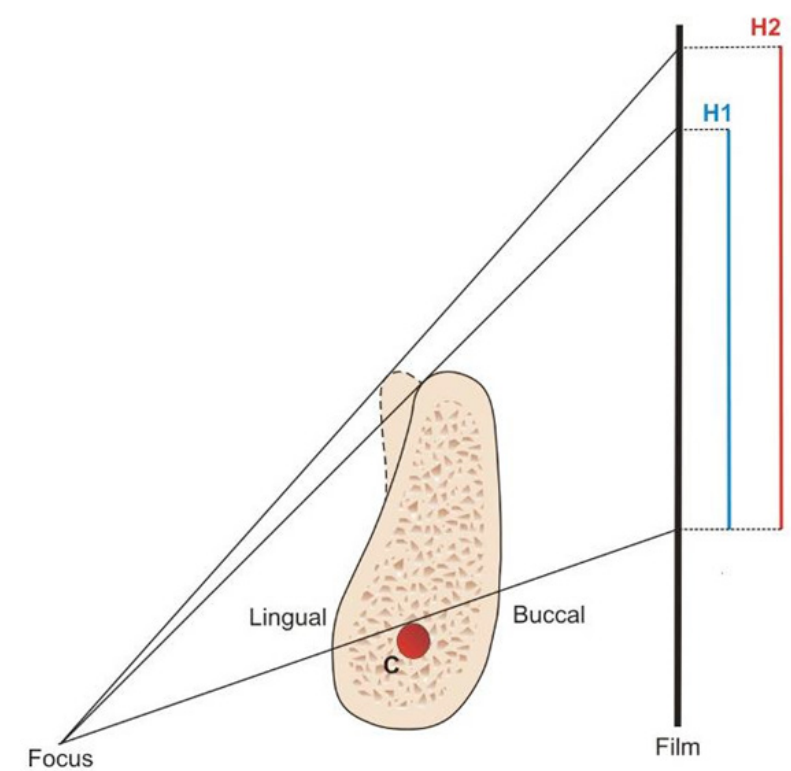

Figure 3. Asymmetry or reshape of the crestal bone influences the height (H1 and $\mathrm{H} 2)$ of bone, apparently available for the implant accommodation above the canal $(\mathrm{C})$, as it was seen on the panoramic film. 
less distance between the buccal aspect of the canal and the buccal mandibular border [31]. Placement of implant buccally or lingually to the MC is a risky approach and should not be attempted unless the clinicians have the aid of computed tomography (CT) and is confident of executing the surgery [ 6$]$.

In panoramic radiograph, the position of $\mathrm{MC}$ in horizontal plane can influence the apparent amount of bone available for implant placement [32]. For example, if the MC lies close to the lingual cortex, it will be projected higher on the film and therefore appear higher in the arch than it really is (Figure 4). In case, where a large mandibular torus is present, it may project significantly to the lingual side of the mandibular body, and its shadow will project upward onto the film, giving a misleading impression of the available bone height [32].

\section{Radiological detection of mandibular canal (MC)}

The location and configuration of $\mathrm{MC}$ are important in imaging diagnosis for the proper dental implant placement in the mandible [33-36]. The MC is usually identifiable on radiographs as a narrow radiolucent ribbon bordered by radio-opaque lines. Periapical radiographs have been used for many years to assess the jaws pre- and post-implant placement [37]. The long cone paralleling technique for taking periapical X-ray is the technique of choice for the following reasons: reduction of radiation dose; less magnification; a true relationship between the bone height and adjacent teeth is demonstrated. It should be noted that for the long cone paralleling technique, it should be taken with a filmfocal distance of approximately $30 \mathrm{~cm}$ [38]. One of the shortcomings of the present method is the use of film. Since the film is highly flexible, literally and figuratively, its processing can be suboptimal and it often leads poor image. Furthermore, maintaining a darkroom requires space and time as well as the additional environmental expenses [37].

During the last decade, many dental practices replaced the film with digital imaging systems. Common reasons for making this transition included improved patient education, lower exposure, greater speed of obtaining images, and the perception of being up to date in the eyes of patients $[12,34]$.

Nevertheless, the biggest concern of periapical radiographs is in $28 \%$ of patients that MC could not be clearly identified in the second premolar and first molar regions [38]. Furthermore, the angulation of the periapical film can affect the perceived location of the canal with respect to the bone crest [39]. In case, when $\mathrm{X}$-ray beam is perpendicular to the canal, but not the film, elongation occurs, and the canal appears further

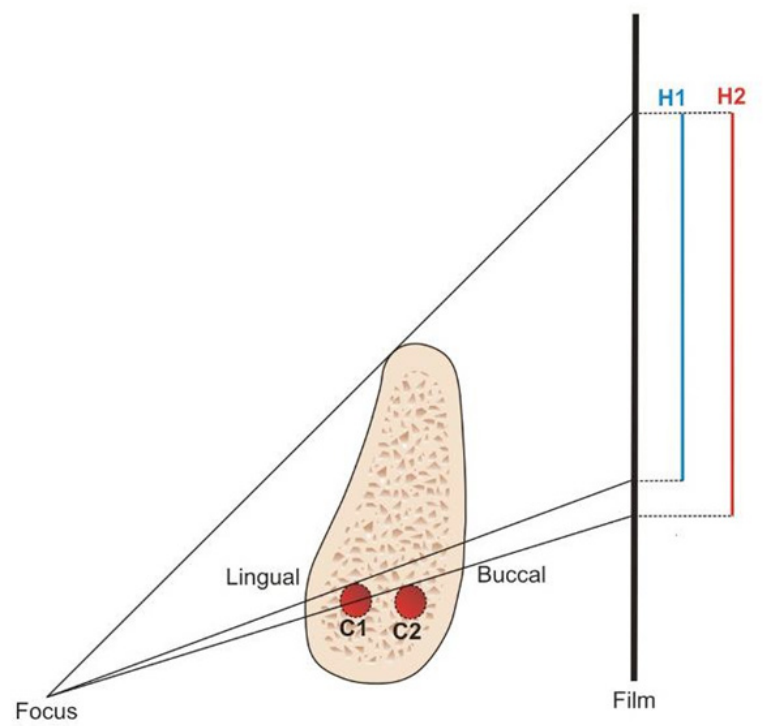

Figure 4. The position of mandibular canal $(\mathrm{C} 1$ and $\mathrm{C} 2)$ in horizontal plane influences the apparent height $(\mathrm{H} 1$ and $\mathrm{H} 2)$ of bone available for implant accommodation.

from the crest than it really is. Conversely, when the $\mathrm{X}$-ray beam perpendicular to the film, but is not parallel to the canal, foreshortening happens [4].

When a specific region that is too large to be seen on a periapical view, panoramic radiograph can be the method of choice. The major advantages of panoramic images are the broad coverage of oral structures, low radiation exposure (about $10 \%$ of a full-mouth radiographs), and relatively inexpensive of the equipment. The major drawbacks of panoramic imaging are: lower image resolution, high distortion, and presence of phantom images. These can artificially produce apparent changes thus may hide some of important vital structures [12]. For example, cervical spine images often overlap on the anterior mandible.

Wadu et al. [40], studying MC appearance on the panoramic radiographs, found that the number of cases of radio-opaque border was either disrupted or even absent. The superior border was more prone to disruption than the inferior border (Figure 5).

In osteoporotic or thin trabeculae mandible, the best method for properly identifying the $\mathrm{MC}$ is either via $\mathrm{CT}$ cross-sectional or CBCT images or scalloping of the cortical plate on the endosteal surface. This is because when in close proximity of lingual cortical plate, the MC may lie in a groove in the endosteal aspect of the cortical bone. On some occasion, the MC will not appear as a circumscribed area of reduced density, but as a circumscribed area of increased density [ $\underline{5}]$.

Though the contrast enhancement application to the digital images improved significantly diagnostic image quality [41], but the use of digital panoramic images did not improve the depiction of the MC [36]. Furthermore, 
Naitoh et al. [36] concluded that the MC borders depiction on digital panoramic images was related to the bone density in alveolar region assessed using multislice $\mathrm{CT}$ images. They found that $\mathrm{MC}$ visible in superior and inferior wall was only $36.7 \%$. Similarly, Lindh et al. [42] reported that the MC of specimen cadavers was clearly visible in $25 \%$ of panoramic radiographs (range 12 to $86 \%$ ). Klinge et al. [43] also reported that the MC of specimen cadavers was not visible in $36.1 \%$ of panoramic radiographs.

CT values (Hounsfield units: $\mathrm{HU}$ ) and bone mineral densities obtained by medical CT were used to assess the bone density of

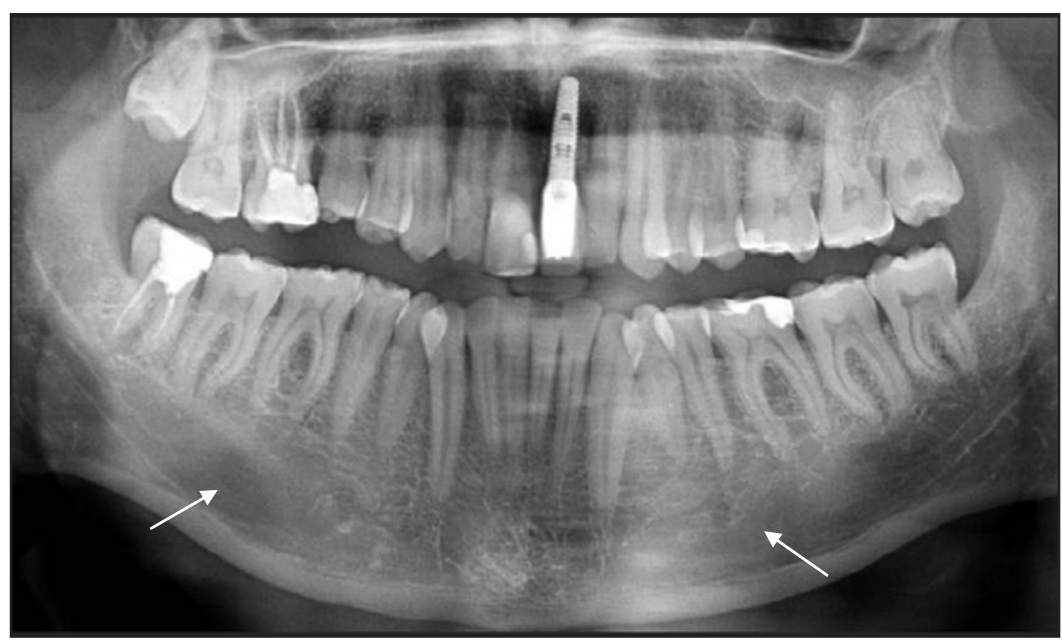

Figure 5. The orthopantomograph shows the disrupted (arrows) superior border of mandibular canal and cancellous bone which has few and thin trabecullae. jaws [44-46]. Norton and Gamble [45] measured the bone density in the posterior mandible using SimPlant software (3D Diagnostix, Boston, MA, USA) and concluded that the mean CT value was 669.6 HU. Misch [44] classified cancellous bone density into 5 grades: D1: > $1250 \mathrm{HU}$; D2: 850 to $1250 \mathrm{HU}$; D3: 350 to $850 \mathrm{HU}$; D4: 150 to $350 \mathrm{HU}$; and D5: < $150 \mathrm{HU}$. In the conversion of $\mathrm{CT}$ values (HU), the mean value in the molar region was $4.5 \times 10^{2}(\mathrm{D} 3)$ : in the first molar region it was $5.2 \times 10^{2}(\mathrm{D} 3)$, in second molar region 4.3 $\mathrm{x} 10^{2}(\mathrm{D} 3)$, and in the third molar region it was $0.7 \mathrm{x}$ $10^{2}$ (D5).

The measurements of bone density in designed sites are critical in presurgical planning when using CBCT for dental implant treatment. However, the pixel or voxel values obtained from CBCT images are not absolute values. Naitoh et al. [36] reconstructed the cross-sectional images of cone-beam and multislice CT and calculated the values of regions-of-interest in 16 images. A high-level correlation between voxel values of CBCT and bone mineral densities of multislice CT was observed $(r=0.965)$. They concluded that voxel values of mandibular cancellous bone in CBCT could be used to estimate bone density.

Another attempt to improve depiction of the MC was by changing the thickness of double-oblique computed tomography images [47]. A total of 38 sites in the mandibular molar region were examined using multislice helical CT. The thicknesses of the doubleoblique images using multislice helical CT scans were reconstructed in 4 conditions: $0.3 \mathrm{~mm}, 0.9 \mathrm{~mm}, 1.6 \mathrm{~mm}$, and $4.1 \mathrm{~mm}$. In the alveolar crest and the entire MC, highest value was obtained with $0.9 \mathrm{~mm}$ thick images; however, there was no significant difference between 0.3 $\mathrm{mm}$ and $0.9 \mathrm{~mm}$ thick images. Authors then concluded that the description of superior wall of MC cannot be improved by changing the thickness of images.

However, the measurements obtained from computed tomographic images are more consistent with direct measurements than the measurements obtained from panoramic radiographic images or conventional tomographic images (Figure $6 \mathrm{~A}$ and $\mathrm{B}$ ). This conclusion was made by Peker et al. [48] after the comparison of efficiency of panoramic radiographs, conventional tomograms, and computed tomograms for location of the MC for 12 regions of 6 dry adult human skulls. Furthermore, Rouas et al. [49] reported that the atypical MC such as bifid MC, in most cases can be identified using only three-dimensional imaging techniques. It was thought that the bifid MC is often left unrecognized [50]. Although, duplication or division of the canal was found, via panoramic radiographs, in about $1 \%$ of patients [27,51-53]. Naitoh et al. [54] reconstructed 122 two-dimensional images of the various planes in mandibular ramus region to the computer program using three-dimensional visualization and measurement software. Bifid MC in the mandibular ramus region was observed even in $65 \%$ of patients.

When the periapical radiography, panoramic radiography, tomography, or CT were compared for their efficiency in the identification of the MC, the CBCT seems to have the most potential while reduces radiation exposure considerably. Angelopoulos et al. [55] compared CBCT reformatted panoramic images with direct (charge-coupled device-based) panoramic radiographs and digital panoramic radiographs based on a storage phosphor system. They concluded that the CBCT reformatted panoramic images outperformed the digital panoramic images in the identification of the MC. Due to the fact that the CBCT images were reformatted slices of the mandible, they were free of magnification, superimposition of neighbouring structures, and other problems inherent to the panoramic radiology. It has also been shown that the CBCT had more accuracy and reproducibility of measurements of $\mathrm{MC}$ when compared 


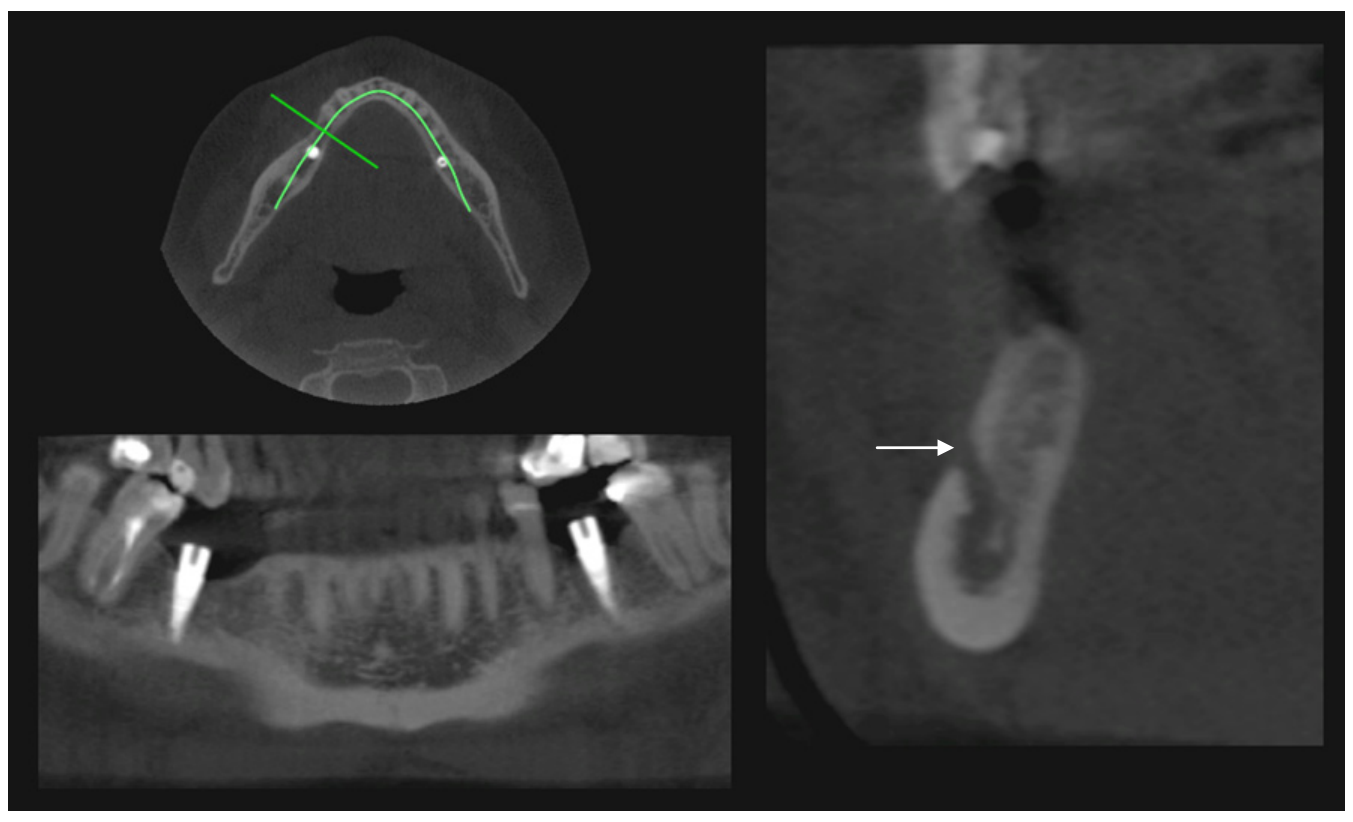

Figure 6 A. Computed tomographic images: mental foramen (arrow) detection.

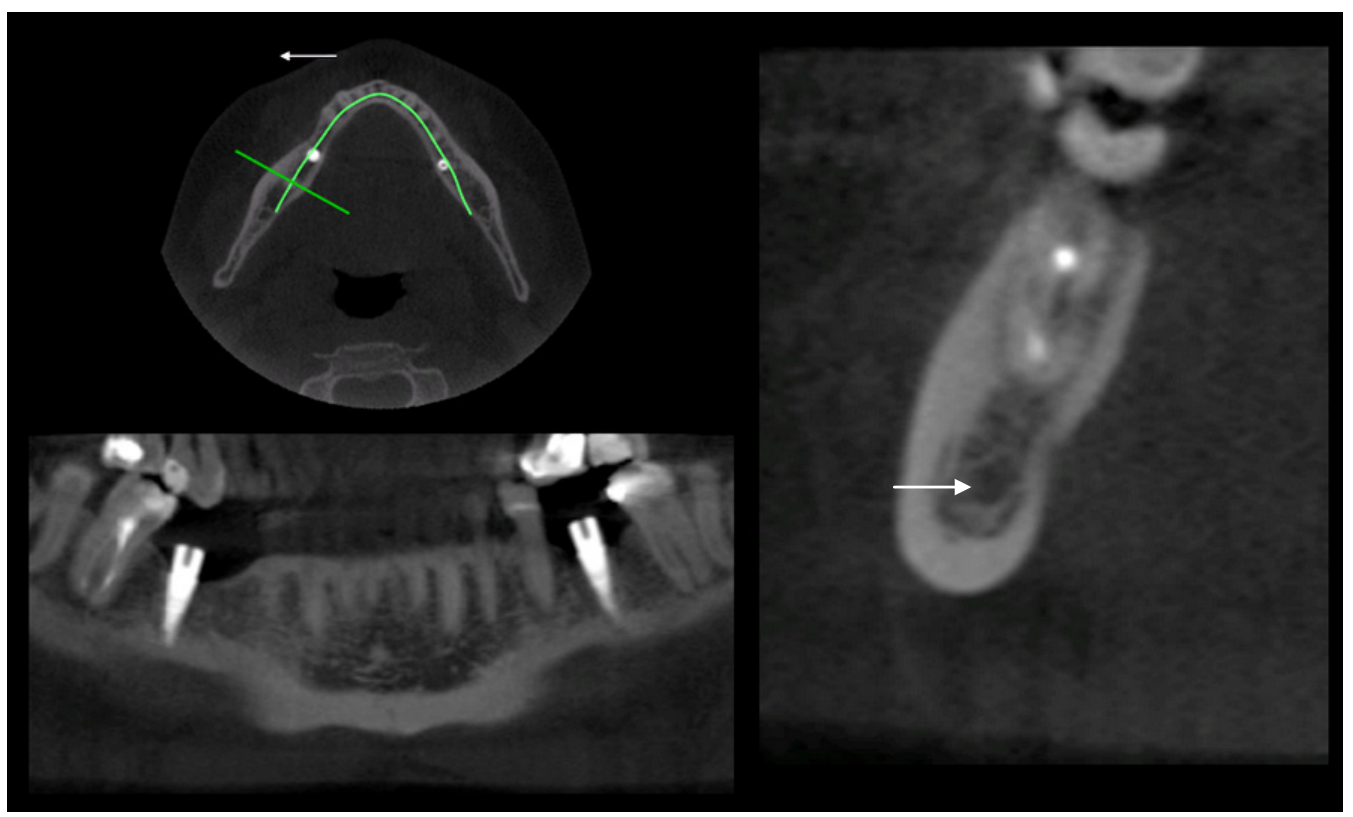

Figure 6 B. Computed tomographic images: mandibular canal detection (arrow).

to direct digital calliper measurements [56]. Basically, the intraclass correlation coefficients for $\mathrm{CBCT}$ and the direct digital calliper ranged from 0.61 to 0.93 for the first observer and from 0.40 to 0.95 for the second observer.

\section{Peculiarities of mental foramen (MF) clinical anatomy}

One of the most challenged regions for implantation in mandible is MF region. This is because there are many variations with regards to the size, shape, location and direction of the opening of the MF. The shape of MF can be round or oval: diameter ranges from 2.5 to
$5.5 \mathrm{~mm}$ [57-59,60-64]. The location of MF differs in the horizontal and vertical planes. The most popular method for the identification of MF in the horizontal plane was proposed by Green [65]. The position of MF was recorded as either in the line with the longitudinal axis of a tooth or as lying between the two teeth. It was shown in number of studies that the location of MF is related with race. For example, the position of MF in the Mongoloid population was in the line with longitudinal axis of the second lower premolar. Their positions in Caucasoid samples were just mesial to those in Chinese, Melanesian, Asian Indians, Thai, Korean, Saudi and Tanzanian samples $[\underline{34}, \underline{57}, \underline{58}, \underline{63}, \underline{66-70}]$.

When planning dental implant operation, clinicians 
should identify vertical MF position, because after the extraction of teeth and resorption of alveolar bone, the MF is closer to the alveolar crest [59,71]. In extreme degrees of resorption, the mental nerve and the final part of inferior alveolar nerve were found directly under the gums. In such cases the initial incision should be made more lingually and a full-thickness flap is elevated until the MF is identified [72].

When examined the vertical MF position in relation to the premolars root apices of 936 patients, Fishel et al. found that the MF was situated coronal to the apex in $38.6 \%$ of cases, at the apex in $15.4 \%$ of cases, and apical to the apex in $46.0 \%$ of cases [66]. For second premolar, MF was coronal to the apex in $24.5 \%$ of cases, $13.9 \%$ at the apex, and $61.6 \%$ apical to the apex. Due to $25 \%$ to $38 \%$ of the foramen is located coronal to the premolars apex, this may create challenge in immediate implant placement especially in the premolar areas [66]. The opening of MF can be done in many different locations such as superiorly, posterosuperiorly, labially, mesially (anteriorly), and posteriorly [58,62,63, 73, 74].

In addition, it was reported, that MF can be more than 1 and this is often related to the race $[\underline{68}, \underline{75}, \underline{76}, \underline{77}]$. For example, the accessory MF was found less frequently in American White (1.4\%) and Asian Indian (1.5\%) populations when compared to African Americans $(5.7 \%)$ and pre-Columbian Nazca Indians (9.0\%). [75]. CBCT has showed that accessory MF tended to exist in the apical area of the first molar and posterior or inferior area of the MF [ 76]. If the MF is in close proximity to the alveolar crest or has atypical anatomy radiographically, to locate the MF properly and to avoid mental nerve damage, it should be done surgically. Some clinicians $[48,79]$ are proposing nerve transposition during the implant placement when there is insufficient EJS dimension. Nevertheless, this approach is not popular due to a high rate of sensory dysfunction postoperatively [80-82].

\section{Radiological mental foramen (MF) detection}

Periapical radiograph is a good tool for the MF detection not only because it reduces skin dose, limits magnification, but it also can be used to establish a true relationship between the bone height and adjacent teeth. However, they are shortcomings associated with periapical radiographs. First of all, a slight image distortion can occur due to angulation and this may account for inability to detect the foramen [60]. Secondary, when MF is located below the apex, it can be difficult to show [66]. Third, in thin mandibular bone it cannot properly identify the MF due to a lack of radiographic contrast $[\underline{57}, \underline{60}]$. Because of the above shortcomings, MF can be identified around $47-75 \%$ cases $[66, \underline{83}]$. To overcome this problem, a combination of horizontal periapical film together with a panoramic image has been suggested [84].

In contrast, Yosue and Brooks [60] detected the MF on $87.5 \%(n=297)$ of panoramic radiographs, and it was distinct $64 \%$ of the time. They classified the appearance of the MF on panoramic radiographs as a continuous, separated, diffuse, or unidentified type. In a sample of 297 patients, the most frequent appearance was separated (43\%), followed by diffuse (24\%), continuous (21\%), and unidentified (12\%). Similarly, Jacobs et al. [85] detected the MF on 94\% $(n=545)$ of panoramic radiographs, but the clear visibility was attained only $49 \%$ of the time. After comparison of the anatomical and radiological assessment of 4 cadaver skulls, Yosue and Brooks [60] concluded that the panoramic and periapical films reflected the actual position of foramen in the skulls $<50 \%$ the time. Furthermore, Sonick et al. [86] found that the average linear errors occurred during routine bone assessments $(n=12)$ for panoramic films were $24 \%$ (mean $3 \mathrm{~mm}$; range 0.5 to $7.5 \mathrm{~mm}$ ), for periapical films were $14 \%$ (mean $1.9 \mathrm{~mm}$; range 0.0 to $5.0 \mathrm{~mm}$ ) and only $1.8 \%$ (mean $0.2 \mathrm{~mm}$; range 0.0 to $0.5 \mathrm{~mm}$ ) for CT scans. Hence, it is concluded that CT scans are more accurate than conventional radiographs $[\underline{43}, \underline{85-88}]$. However, the limitations of cross-sectional imaging are: limited availability, high cost and the need for image interpretation $[89,90]$. However, CBCT is often recommended for clinical usage, especially in cases there the vital structures are difficult to detect due to its high accuracy and low radiation exposure $[\underline{17}, \underline{18}, \underline{19}, \underline{91}]$. For example, Naitoh et al. [ㄱ] studied CBCT images of 157 patients and found the accessory MF observed in $7 \%$ of patients. There was no significant difference regarding the sizes of MF between accessory MF presence and absence. Also, the mean distance between the mental and accessory MF was $6.3 \mathrm{~mm}$ (SD $1.5 \mathrm{~mm}$ ).

The main advantage of CBCT is a low dose scanning system, which has been specifically designed to produce three-dimensional images of the maxillofacial skeleton $[92,93]$. Remarkably, in most systems scan times of less than 20 seconds can be achieved using personal computers. Hence, a major difference between CT and CBCT is how the data are gathered: CT acquires image data using rows of detectors, CBCT exposes the whole section of the patient over one detector $[92,93]$.

\section{Peculiarities of anterior loop (AL) of mental nerve clinical anatomy}

When inferior alveolar nerve arises from the MC, it runs outward, upward and backward to open at the MF then it was called as AL [94-98]. This means that the MN, 
however, may extend beyond the MF boundary as an intraosseous AL. The most objective evidence for the presence of AL is examination of dissected cadaver mandibles. For example, Solar et al. [73] AL detected in $60 \%$ (22 of 37) of dissected cadaver mandibles, ranging in length from 0.5 to $5 \mathrm{~mm}$ (mean $1 \mathrm{~mm}$ ); Neiva et al. [57] AL detected in $88 \%(n=22)$, ranging in length from 1 to $11 \mathrm{~mm}$ (mean $4.13 \mathrm{~mm}$ ); Rosenquist [99] detected $\mathrm{AL}$ in $24 \%$ (15 of 58) ranging in length from 0 to $1 \mathrm{~mm}$. In clinical practice possible presence of an AL should be identified radiographically before the implant placement. Additionally, clinician can probe the MF to ascertain if there is an AL during surgical operation. In this regard, a curved probe (e. g., Naber's $2 \mathrm{~N}$ probe) can be gently placed into the foramen to assess if its distal aspect is open. If it is not open, then the nerve entered on the mesial side, and this denotes that an $\mathrm{AL}$ is present []. Otherwise, it is not possible to distinguish between the patency of the mesial aspect of the MF leading to the incisal region and an AL because those two structures feel similar [97]. Furthermore, neurologic damage can be induced to the nerve when the length of an $A L$ is not clear. If there is no possibility to obtain accurate information about mental nerve with CT or CBCT, it was recommended to place the implant $6 \mathrm{~mm}$ anterior to the MF to avoid causing the nerve damage [73]

\section{Radiological anterior loop (AL) of mental nerve detection}

Using radiographic methods to assess an anterior mental loop revealed large variations. Bavitz et al. [96] reported that the AL was present in 54\% (17 of 35) of periapical radiographs taken of hemi-mandibles. However, this finding was only confirmed by dissection in $11 \%$ (4 of 35 ) of the corresponding cadaver specimens. Loop sizes ranged from 0.0 to $7.5 \mathrm{~mm}$ on periapical radiographs and from 0 to $1.0 \mathrm{~mm}$ among cadaver specimens. Mardinger et al. [100] assessed 46 hemi-mandibles using periapical films and dissection with physical evaluation. No correlation was found between the radiographic image and the anatomical shape of the loop. Also, $70 \%$ of the radiographically diagnosed loops, $40 \%$ were not seen in anatomical examination.

Yosue and Brooks [60] examined 297 panoramic radiographs and noted that an AL (termed continuous type MF in their study) was present only $21 \%$. Misch and Crawford [101] noted an AL average length was $5 \mathrm{~mm}$ in $12 \%$ of 324 patient's panoramic radiographs. Arzouman et al. [95] looked at the 25 adult skulls using panoramic, with and without radiopaque markers placed into the $\mathrm{MC}$ and $\mathrm{AL}$. The $\mathrm{AL}$ was also recorded directly using flexible tubing ( $2 \mathrm{~mm}$ in diameter). Significantly fewer loops were detected in radiographs as compared with anatomical assessment $(\mathrm{P}<0.001)$. A significant loop (>2 mm) was identified in $92 \%$ to $96 \%$ of the direct measurement, whereas panoramic radiographs identified only $56 \%$ and $76 \%$ with and without radiopaque markers, respectively. The average length of the AL based on direct measurements was $6.95 \mathrm{~mm}$, whereas radiographic measurements were $3.18 \mathrm{~mm}$ and 3.45 $\mathrm{mm}$ using different panoramic machine. Kuzmanovic et al. [98] compared visual interpretation of the panoramic radiographs with anatomical dissection findings in 22 cadavers. AL of the mental canal was only identified in 6 panoramic radiographs (27\%) (range 0.5 to $3 \mathrm{~mm}$ ) and $8(35 \%)$ in anatomical measurements. Jacobs et al. [85] examined 545 patient's panoramic radiographs and found an $\mathrm{AL}$ in $11 \%$ of cases, but was well visualized in only $3 \%$ of the detected loops. Ngeow et al. [70] reported that the AL was only visible in $39(40.2 \%)$ panoramic radiographs. Authors then concluded that the panoramic is not sufficient for presurgical implant planning in the mental region and there is a need for other additional images. Jacobs et al. [102] examined 230 spiral CT scans taken for preoperative planning of implant placement in the posterior mandible where the $\mathrm{AL}$ appeared in $7 \%$ of cases. However, according to Rothman [103] the appearance of AL on CT scans can be described precisely. Uchida et al. supported Rothman's point of view [104], who used CBCT in 4 cadavers and dissected 71 cadavers. The anatomical measurements revealed the mean AL size of $1.9 \pm 1.7 \mathrm{~mm}$ (ranged 0.0 to $9.0 \mathrm{~mm}$ ). The average discrepancies between CBCT and anatomical measurements were $0.06 \mathrm{~mm}$ or less. Investigations that compared radiographic and cadaveric dissection data with respect to identifying the AL reported that radiographic assessments result in a high percentage of false-positive and false-negative findings $[\underline{95}, \underline{96}, \underline{98-100}]$. Varied findings might be attributed to different criteria used to define the AL, dissimilar diagnostic techniques, and diverse findings in patients [4].

\section{Peculiarities of mandibular incisive canal (MIC) clinical anatomy}

MIC, a continuation of MC, has been identified in several reports $[\underline{71}, \underline{85}, \underline{105}, \underline{106]}$. Mraiwa et al. [71] reported MIC was macroscopically observed in $96 \%$ of 50 cadavers' mandibles with mean (SD) inner diameter of $1.8(0.5 \mathrm{~mm})$. The MIC was located on average $9.7 \mathrm{~mm}$ (SD $1.8 \mathrm{~mm}$ ) from the lower cortical border and continued towards the incisor region in a slightly downward direction, with a mean (SD) distance to the lower cortical border of $7.2(2.1) \mathrm{mm}$. The canal was narrowing crossing the midline and reached only the midline in $18 \%$ of cases. The MIC was terminating 
apically to the lateral incisor and sometimes apically to the central incisor. The diameter of MIC ranged from 0.48 to $6.6 \mathrm{~mm}$. Mardinger et al. [100] found MIC in all 46 cadavers' specimens, travelling within the canal. De Andrade with co-authors [106] concluded that, the MIC is a normal structure that typically extends closer to the mandibular midline. The incisive nerve supplies innervation to first bicuspid, canine, lateral incisors and central incisors.

In case of large MIC, a patient may experience discomfort during osteotomy or experience postoperative pain that requires no implant insertion or implant removal [107109].

\section{Radiological mandibular incisive canal (MIC) detection}

Mardinger et al. [100] defined the anatomic and radiographic courses of MIC in 46 cadavers' hemimandibles. They distinguished the canals into complete $(\mathrm{n}=10)$, partial $(\mathrm{n}=27)$, or no $(\mathrm{n}=9)$ bony cortical borders. Furthermore, the canal was either well defined $(n=11,24 \%)$, poorly defined $(n=15,32 \%)$, or undetectable $(n=20,44 \%)$ using the panoramic radiography. It was concluded that statistically significant correlation was found between the anatomic structure of the MIC bony borders and its radiographic detectability $(\mathrm{P}=0.043)$. However, Jacobs with coworkers [102] reported that the MIC was identified only in $15 \%$ of the 545 panoramic radiographs, with good visibility of only $1 \%$. In contrast, canal was observed on $93 \%$ of CT scans with a good visibility in $22 \%$ of cases. Uchida et al. found that the MIC diameter ranged from 1.0 to $6.6 \mathrm{~mm}$ with SD of $2.8 \pm 1.0 \mathrm{~mm}$ [104] and confirmed the reliability of $\mathrm{CBCT}$ in detecting MIC. Pires et al. [110] later agreed with Uchida et al. and reported that the MIC parameters are better determined by CBCT $(83 \%)$ than by panoramic radiography (11\%). The range of MIC diameter was from $0.4 \times 0.4$ $\mathrm{mm}$ to $4.6 \times 3.2 \mathrm{~mm}$. The mean length of canal was $7 \pm 3.8 \mathrm{~mm}$. The distance from the inferior border of mandible to the canal was $10.2 \pm 2.4 \mathrm{~mm}$, and the mean distance to the buccal plate was $2.4 \mathrm{~mm}$. The apex-canal distance (in dentate subjects) was $5.3 \mathrm{~mm}$. Therefore, it is recommended to use conventional tomographs or CBCT for better imaging of the interforaminal area.

\section{Guidelines to identify mandibular vital structures}

The goal of planning for dental implant operation is that clinicians should have clear three-dimensional vision of the EJS. This can be achieved by combining the practical knowledge of basic mandibular anatomy and data obtained from clinical and radiological examination. The following are recommendations for properly planning implant surgery in the mandible especially in the areas of vital structures.

\section{Mandibular canal region}

1. Consider the influence of bony crestal anatomy. If there is a need to re-shape the crestal ridge in order to accommodate future implant placement then it is important to deduct 1 to $3 \mathrm{~mm}$ from the calculation or plan to perform ridge augmentation.

2. Buccolingual position of the crestal peak of bone can influence the reliability on intraoral or panoramic radiograph in vertical plane.

3. The buccolingual position of the MC can influence $\mathrm{MC}$ position in vertical plane on panoramic radiograph. 4. If large mandibular torus is present it may create false impression on the amount of the available bone height as well as difficult to depict MC borders.

\section{Mental foramen region}

6. In cases where the extreme ridge resorption existed, the initial incision should be made more to the lingual and a full-thickness flap is elevated until the MF is identified.

7. Be aware of $25 \%$ to $38 \%$ of cases, the MF is located coronal to the premolars apex.

8. The best approach to locate MF is surgical access.

\section{Anterior loop of the mental nerve region}

9. The MN may extend beyond the MF boundary.

10. Clinician should probe MF gently to ascertain if there is an AL during surgical operation.

11. If $\mathrm{CT}$ or $\mathrm{CBCT}$ cannot provide accurate information on mental nerve location and its pathway, the distal aspect of dental implant should be placed $6 \mathrm{~mm}$ anterior to the MF to avoid potential nerve damage.

\section{Mandibular incisive canal region}

12. The large MIC should be taken into account in patients who developed discomfort during osteotomy or after implant placement.

Many radiographic methods, including periapical, panoramic, conventional CT [13], and CBCT [16-19], have been recommended for the pre-implant treatment planning. The CT scan was developed to overcome the drawback, lack of cross-sectional information, noted in the conventional radiography (periapical and panoramic) $[2, \underline{14}, 111]$. Due to the ability of precisely identifying anatomical landmarks, high accuracy and 
low radiation exposure, $\mathrm{CBCT}$ has been suggested to be the main method for radiographic pre-implant planning tool [16-19].

The following recommendations are made with regards to radiographical assessment during the implant presurgical planning.

\section{Periapical radiography}

1. The long cone paralleling technique is the technique of choice for taking periapical radiographs. To be accurate, a film-focal distance should not go beyond 30 $\mathrm{cm}$.

2. The drawback for periapical radiography is using film. Because the film is highly flexible, literally and figuratively, it's processing is often suboptimal, with deleterious consequences to the image quality.

3 . The angulation can cause distortion.

4. $28 \%$ of patients, MC could not be clearly identified in the second premolar and the first molar regions.

5. In cases where the MF is located in low position, periapical film or digital sensor cannot properly locate its position.

\section{Panoramic radiography}

6. Panoramic can provide wide coverage of the oral structures, relatively low radiation exposure (as compared to full-mouth periapical X-rays), and moderately low expense of the equipment.

7. The major limitations of panoramic are: lower resolution, higher distortion, potential of overlapping anatomical structures, image is often related to the bone density and difficult to accurately identify vital structures.

8. To compensate distortions, a pre-known marker is needed for calculation of magnification $\%$.

9. A minimal of $2 \mathrm{~mm}$ safety zone away from the vital structures is often recommended to avoid future nerve damage.
Computer tomography and cone beam computer tomography

10. So far, computed tomographic (CT or CBCT) images are more consistent with direct measurements. The advantages of CBCT are: low exposure, high accuracy, three-dimensional image, and a low dose scanning system.

11. The main limitations of cross-sectional imaging are: limited availability, difficulty in image interpretation, and high cost.

12. The CT and CBCT differ in how the data are gathered: $\mathrm{CT}$ acquires image data using rows of detectors and CBCT exposes the whole section over one detector.

\section{CONCLUSIONS}

Prior to commencement of the implant surgery, careful and detailed planning is required to identify mandibular vital structures as well as the shape and dimensions of the bone. The decision on which image is the most appropriate for each case should be based upon the radiation involved, the cost, and the reliability of each examination method. At current, it appears the cone beam computed tomography showed the great potential for proper pre-implant planning. The guidelines proposed here serve as a tool to assist clinicians in properly identifying mandibular vital structures while providing information related to the current used radiographic techniques.

\section{ACKNOWLEDGMENTS AND DISCLOSURE STATEMENTS}

The authors report no conflicts of interest related to this study.

\section{REFERENCES}

1. Givol N, Taicher S, Halamish-Shani T, Chaushu G. Risk management aspects of implant dentistry. Int J Oral Maxillofac Implants. 2002 Mar-Apr;17(2):258-62. [Medline: 11958409]

2. Kalpidis CD, Setayesh RM. Hemorrhaging associated with endosseous implant placement in the anterior mandible: a review of the literature. J Periodontol. 2004 May;75(5):631-45. [Medline: 15212344] [doi: 10.1902/jop.2004.75.5.631]

3. Abarca M, van Steenberghe D, Malevez C, De Ridder J, Jacobs R. Neurosensory disturbances after immediate loading of implants in the anterior mandible: an initial questionnaire approach followed by a psychophysical assessment. Clin Oral Investig. 2006 Dec;10(4):269-77. [Medline: 16937108] [doi: 10.1007/s00784-006-0065-0] [FREE Full Text]

4. Greenstein G, Tarnow D. The mental foramen and nerve: clinical and anatomical factors related to dental implant placement: a literature review. J Periodontol. 2006 Dec;77(12):1933-43. [Medline: 17209776] [doi: 10.1902/jop.2006.060197] 
5. Monsour PA, Dudhia R. Implant radiography and radiology. Aust Dent J. 2008 Jun;53 Suppl 1:S11-25. [Medline: 18498579] [doi: 10.1111/j.1834-7819.2008.00037.x]

6. Greenstein G, Cavallaro J, Romanos G, Tarnow D. Clinical recommendations for avoiding and managing surgical complications associated with implant dentistry: a review. J Periodontol. 2008 Aug;79(8):1317-29. [Medline: 18672980] [doi: 10.1902/jop.2008.070067]

7. Juodzbalys G, Wang HL, Sabalys G. Anatomy of Mandibular Vital Structures. Part I: Mandibular Canal and Inferior Alveolar Neurovascular Bundle in relation with Dental Implantology. J Oral Maxillofac Res 2010;1(1):e2. URL: http://www.ejomr.org/JOMR/archives/2010/1/e2/e2ht.htm [doi: 10.5037/jomr.2010.1102]

8. Juodzbalys G, Wang HL, Sabalys G. Part II: Mandibular Incisive Canal, Mental Foramen and Associated Neurovascular Bundles in Relation with Dental Implantology. J Oral Maxillofac Res 2010;1(1):e3. URL: http://www.ejomr.org/JOMR/archives/2010/1/e3/e3ht.htm [doi: 10.5037/jomr.2010.1103]

9. Garg AK, Vicari A. Radiographic modalities for diagnosis and treatment planning in implant dentistry. Implant Soc. 1995;5(5):7-11. [Medline: 9571835]

10. Harris D, Buser D, Dula K, Grondahl K, Haris D, Jacobs R, Lekholm U, Nakielny R, van Steenberghe D, van der Stelt P; European Association for Osseointegration. E.A.O. guidelines fo the use of diagnostic imaging in implant dentistry. A consensus workshop organized by the European Association for Osseointegration in Trinity College Dublin. Clin Oral Implants Res. 2002 Oct;13(5):566-70. [Medline: 12674118] [doi: 10.1034/j.1600-0501.2002.130518.x]

11. Schropp L, Wenzel A, Kostopoulos L. Impact of conventional tomography on prediction of the appropriate implant size. Oral Surg Oral Med Oral Pathol Oral Radiol Endod. 2001 Oct;92(4):458-63. [Medline: 11598584] [doi: 10.1067/moe.2001.118286]

12. White SC, Heslop EW, Hollender LG, Mosier KM, Ruprecht A, Shrout MK. American Academy of Oral and Maxillofacial Radiology, ad hoc Committee on Parameters of Care. Parameters of radiologic care: An official report of the American Academy of Oral and Maxillofacial Radiology. Oral Surg Oral Med Oral Pathol Oral Radiol Endod. 2001 May;91(5):498511. [Medline: 11346726] [doi: 10.1067/moe.2001.114380]

13. Pharoah MJ. Imaging techniques and their clinical significance. Int J Prosthodont. 1993 Mar-Apr;6(2):176-9.

14. BouSerhal C, Jacobs R, Quirynen M, van Steenberghe D. Imaging technique selection for the preoperative planning of oral implants: a review of the literature. Clin Implant Dent Relat Res. 2002;4(3):156-72. [Medline: 12516649] [doi: 10.1111/j.1708-8208.2002.tb00167.x]

15. Almog DM, Romano PR. CT-based dental imaging for implant planning and surgical guidance. N Y State Dent J. 2007 Jan;73(1):51-3. [Medline: 17378318]

16. Vazquez L, Saulacic N, Belser U, Bernard JP. Efficacy of panoramic radiographs in the preoperative planning of posterior mandibular implants: a prospective clinical study of 1527 consecutively treated patients. Clin Oral Implants Res. 2008 Jan;19(1):81-5. Epub 2007 Oct 22. [Medline: 17956572] [doi: 10.1111/j.1600-0501.2007.01402.x]

17. Lascala CA, Panella J, Marques MM. Analysis of the accuracy of linear measurements obtained by cone beam computed tomography (CBCT-NewTom). Dentomaxillofac Radiol. 2004 Sep;33(5):291-4. [Medline: 15585804] [doi: $10.1259 / \mathrm{dmfr} / 25500850$ ]

18. Sato S, Arai Y, Shinoda K, Ito K. Clinical application of a new cone-beam computerized tomography system to assess multiple two-dimensional images for the preoperative treatment planning of maxillary implants: case reports. Quintessence Int. 2004 Jul-Aug;35(7):525-8. [Medline: 15259967]

19. Almog DM, LaMar J, LaMar FR, LaMar F. Cone beam computerized tomography-based dental imaging for implant planning and surgical guidance, Part 1: Single implant in the mandibular molar region. J Oral Implantol. 2006;32(2):77-81. [Medline: 16704109] [doi: 10.1563/789.1]

20. Garg AK. Dental implant imaging: TeraRecon's Dental 3D Cone Beam Computed Tomography System. Dent Implantol Update. 2007 Jun;18(6):41-5. [Medline: 17682685]

21. Periago DR, Scarfe WC, Moshiri M, Scheetz JP, Silveira AM, Farman AG. Linear accuracy and reliability of cone beam CT derived 3-dimensional images constructed using an orthodontic volumetric rendering program. Angle Orthod. 2008 May;78(3):387-95. [Medline: 18416632] [doi: 10.2319/122106-52.1] [FREE Full Text]

22. Liang X, Jacobs R, Hassan B, Li L, Pauwels R, Corpas L, Souza PC, Martens W, Shahbazian M, Alonso A, Lambrichts I. A comparative evaluation of Cone Beam Computed Tomography (CBCT) and Multi-Slice CT (MSCT): Part I. On subjective image quality. Eur J Radiol. 2009 Apr 30. [Epub ahead of print] [Medline: 19410409] [doi: 10.1016/j.ejrad.2009.03.042]

23. Liang X, Lambrichts I, Sun Y, Denis K, Hassan B, Li L, Pauwels R, Jacobs R. A comparative evaluation of Cone Beam Computed Tomography (CBCT) and Multi-Slice CT (MSCT). Part II: On 3D model accuracy. Eur J Radiol. 2009 May 5. [Epub ahead of print] [Medline: 19423257] [doi: 10.1016/j.ejrad.2009.04.016]

24. Juodzbalys G, Raustia AM. Accuracy of clinical and radiological classification of the jawbone anatomy for implantation--a survey of 374 patients. J Oral Implantol. 2004;30(1):30-9. [Medline: 15008452] [doi: 10.1563/1548-1336(2004)030<0030:AOCARC >2.0.CO;2]

25. Tammisalo T, Happonen RP, Tammisalo EH. Stereographic assessment of mandibular canal in relation to the roots of impacted lower third molarusing multiprojection narrow beam radiography. Int J Oral Maxillofac Surg. 1992 Apr;21(2):85-9. [Medline: 1602166] [doi: 10.1016/S0901-5027(05)80538-7] 
26. Anderson LC, Kosinski TF, Mentag PJ. A review of the intraosseous course of the nerves of the mandible. J Oral Implantol. 1991;17(4):394-403. [Medline: 1813647]

27. Nortjé CJ, Farman AG, Grotepass FW. Variations in the normal anatomy of the inferior dental (mandibular) canal: a retrospective study of panoramic radiographs from 3612 routine dental patients. Br J Oral Surg. 1977 Jul;15(1):55-63. [Medline: 268217] [doi: 10.1016/0007-117X(77)90008-7]

28. Miller CS, Nummikoski PV, Barnett DA, Langlais RP. Cross-sectional tomography. A diagnostic technique for determining the buccolingual relationship of impacted mandibular third molars and the inferior alveolar neurovascular bundle. Oral Surg Oral Med Oral Pathol. 1990 Dec;70(6):791-7. [Medline: 2263343] [doi: 10.1016/0030-4220(90)90023-L]

29. Obradović O, Todorovic L, Vitanovic V. Anatomical considerations relevant to implant procedures in the mandible. Bull Group Int Rech Sci Stomatol Odontol. 1995 Jan-Feb;38(1-2):39-44. [Medline: 7881265]

30. Davis H. Mobilization of the Alveolar Nerve to Allow Placement of Osseointegratible Fixtures. In: Advanced Osseointegration Surgery: Application in the Maxillofacial Region. Chicago: Quintessence Publishing Co.: 2000. p. $129-41$.

31. Levine MH, Goddard AL, Dodson TB. Inferior alveolar nerve canal position: a clinical and radiographic study. J Oral Maxillofac Surg. 2007 Mar;65(3):470-4. [Medline: 17307595] [doi: 10.1016/j.joms.2006.05.056]

32. Worthington P. Injury to the inferior alveolar nerve during implant placement: a formula for protection of the patient and clinician. Int J Oral Maxillofac Implants. 2004 Sep-Oct;19(5):731-4. [Medline: 15508990]

33. Wyatt WM. Accessory mandibular canal: literature review and presentation of an additional variant. Quintessence Int. 1996 Feb;27(2):111-3. [Medline: 9063221]

34. Kim IS, Kim SG, Kim YK, Kim JD. Position of the mental foramen in a Korean population: a clinical and radiographic study. Implant Dent. 2006 Dec;15(4):404-11. [Medline: 17172959] [doi: 10.1097/01.id.0000243319.66845.15]

35. Rueda S, Gil JA, Pichery R, Alcañiz M. Automatic segmentation of jaw tissues in CT using active appearance models and semi-automatic landmarking. Med Image Comput Comput Assist Interv. 2006;9(Pt 1):167-74. [Medline: 17354887] [doi: 10.1007/11866565_21]

36. Naitoh M, Hirukawa A, Katsumata A, Ariji E. Evaluation of voxel values in mandibular cancellous bone: relationship between cone-beam computed tomography and multislice helical computed tomography. Clin Oral Implants Res. 2009 May;20(5):503-6. [Medline: 19250241] [doi: 10.1111/j.1600-0501.2008.01672.x]

37. van der Stelt PF. Filmless imaging: the uses of digital radiography in dental practice. J Am Dent Assoc 2005;136(10):137987. [Medline: 16255462] [FREE Full Text]

38. Denio D, Torabinejad M, Bakland LK. Anatomical relationship of the mandibular canal to its surrounding structures in mature mandibles. J Endod. 1992 Apr;18(4):161-5. [Medline: 1402570] [doi: 10.1016/S0099-2399(06)81411-1]

39. Misch CE. Diagnostic imaging techniques. In: Misch CE, editor. Contemporary Implant Dentistry, 3nd ed. St Louis: CV Mosby Company; 2008. p. 38-67.

40. Wadu SG, Penhall B, Townsend GC. Morphological variability of the human inferior alveolar nerve. Clin Anat. 1997;10(2):82-7. [Medline: 9058013] [doi: 10.1002/(SICI)1098-2353(1997)10:2<82::AID-CA2>3.0.CO;2-V]

41. Gijbels F, De Meyer AM, Bou Serhal C, Van den Bossche C, Declerck J, Persoons M, Jacobs R. The subjective image quality of direct digital and conventional panoramic radiography. Clin Oral Investig. 2000 Sep;4(3):162-7. [Medline: 11000322] [doi: 10.1007/s007840000059]

42. Lindh C, Petersson A, Klinge B. Measurements of distances related to the mandibular canal in radiographs. Clin Oral Implants Res. 1995 Jun;6(2):96-103. [Medline: 7578787] [doi: 10.1034/j.1600-0501.1995.060205.x]

43. Klinge B, Petersson A, Maly P. Location of the mandibular canal: comparison of macroscopic findings, conventional radiography, and computed tomography. Int J Oral Maxillofac Implants. 1989 Winter;4(4):327-32. [Medline: 2639861]

44. Misch CE. Bone density: A key determinant for clinical success. In: Misch CE, editor. Contemporary Implant Dentistry, 2nd ed. St Louis: CV Mosby Company; 1999. p. 109-18.

45. Norton MR, Gamble C. Bone classification: an objective scale of bone density using the computerized tomography scan. Clin Oral Implants Res. 2001 Feb;12(1):79-84. [Medline: 11168274] [doi: 10.1034/j.1600-0501.2001.012001079.x]

46. Naitoh M, Kurosu Y, Inagaki K, Katsumata A, Noguchi T, Ariji E. Assessment of mandibular buccal and lingual cortical bones in postmenopausal women. Oral Surg Oral Med Oral Pathol Oral Radiol Endod. 2007 Oct;104(4):545-50. [Medline: 17689117] [doi: 10.1016/j.tripleo.2007.04.034]

47. Naitoh M, Katsumata A, Hiraiwa Y, Aimiya H, Ohsaki C, Ariji E. Can mandibular depiction be improved by changing the thickness of double-oblique computed tomography images? Implant Dent. 2008 Sep;17(3):271-7. [Medline: 18784527] [doi: 10.1097/ID.0b013e318182d7a4]

48. Peker I, Alkurt MT, Michcioglu T. The use of 3 different imaging methods for the localization of the mandibular canal in dental implant planning. Int J Oral Maxillofac Implants. 2008 May-Jun;23(3):463-70. [Medline: 18700369]

49. Rouas P, Nancy J, Bar D. Identification of double mandibular canals: literature review and three case reports with CT scans and cone beam CT. Dentomaxillofac Radiol. 2007 Jan;36(1):34-8. [Medline: 17329586] [doi: 10.1259/dmfr/27374727]

50. Claeys V, Wackens G. Bifid mandibular canal: literature review and case report. Dentomaxillofac Radiol. 2005 Jan;34(1):55-8. [Medline: 15709108] [doi: 10.1259/dmfr/23146121]

51. Grover PS, Lorton L. Bifid mandibular nerve as a possible cause of inadequate anesthesia in the mandible. J Oral Maxillofac Surg. 1983 Mar;41(3):177-9. [Medline: 6572228] [doi: 10.1016/0278-2391(83)90076-9] 
52. Langlais RP, Broadus R, Glass BJ. Bifid mandibular canals in panoramic radiographs. J Am Dent Assoc. 1985 Jun;110(6):923-6. [Medline: 3860553]

53. Sanchis JM, Peñarrocha M, Soler F. Bifid mandibular canal. J Oral Maxillofac Surg. 2003 Apr;61(4):422-4. [Medline: 12684957] [doi: 10.1053/joms.2003.50004]

54. Naitoh M, Hiraiwa Y, Aimiya H, Ariji E. Observation of bifid mandibular canal using cone-beam computerized tomography. Int J Oral Maxillofac Implants. 2009 Jan-Feb;24(1):155-9. [Medline: 19344041]

55. Angelopoulos C, Thomas SL, Hechler S, Parissis N, Hlavacek M. Comparison between digital panoramic radiography and cone-beam computed tomography for the identification of the mandibular canal as part of presurgical dental implant assessment. J Oral Maxillofac Surg. 2008 Oct;66(10):2130-5. [Medline: 18848113] [doi: 10.1016/j.joms.2008.06.021]

56. Kamburoğlu K, Kiliç C, Ozen T, Yüksel SP. Measurements of mandibular canal region obtained by cone-beam computed tomography: a cadaveric study. Oral Surg Oral Med Oral Pathol Oral Radiol Endod. 2009 Feb;107(2):e34-42. [Medline: 19138636 ] [doi: $10.1016 /$ i.tripleo.2008.10.012]

57. Neiva RF, Gapski R, Wang HL. Morphometric analysis of implant-related anatomy in Caucasian skulls. J Periodontol. 2004 Aug;75(8):1061-7. [Medline: 15455732] [doi: 10.1902/jop.2004.75.8.1061]

58. Apinhasmit W, Chompoopong S, Methathrathip D, Sansuk R, Phetphunphiphat W. Supraorbital Notch/Foramen, Infraorbital Foramen and Mental Foramen in Thais: anthropometric measurements and surgical relevance. J Med Assoc Thai. 2006 May;89(5):675-82. [Medline: 16756055]

59. Gershenson A, Nathan H, Luchansky E. Mental foramen and mental nerve: changes with age. Acta Anat (Basel). 1986;126(1):21-8. [Medline: 3739599] [doi: 10.1159/000146181]

60. Yosue T, Brooks SL. The appearance of mental foramina on panoramic radiographs. I. Evaluation of patients. Oral Surg Oral Med Oral Pathol. 1989 Sep;68(3):360-4. [Medline: 2771380] [doi: 10.1016/0030-4220(89)90224-7]

61. Mbajiorgu EF, Mawera G, Asala SA, Zivanovic S. Position of the mental foramen in adult black Zimbabwean mandibles: a clinical anatomical study. Cent Afr J Med. 1998 Feb;44(2):24-30. [Medline: 9675967]

62. Igbigbi PS, Lebona S. The position and dimensions of the mental foramen in adult Malawian mandibles. West Afr J Med. 2005 Jul-Sep;24(3):184-9. [Medline: 16276691]

63. Fabian FM. Position, shape and direction of opening of the mental foramen in dry mandibles of Tanzanian adult black males. Ital J Anat Embryol. 2007 Jul-Sep;112(3):169-77 [Medline: 18078238]

64. Al-Khateeb T, Al-Hadi Hamasha A, Ababneh KT. Position of the mental foramen in a northern regional Jordanian population. Surg Radiol Anat. 2007 Apr;29(3):231-7. [Medline: 17375258] [doi: 10.1007/s00276-007-0199-z]

65. Green RM. The position of the mental foramen: a comparison between the southern (Hong Kong) Chinese and other ethnic and racial groups. Oral Surg Oral Med Oral Pathol. 1987 Mar;63(3):287-90. [Medline: 3473355] [doi: 10.1016/0030-4220(87)90191-5]

66. Fishel D, Buchner A, Hershkowith A, Kaffe I. Roentgenologic study of the mental foramen. Oral Surg Oral Med Oral Pathol. 1976 May;41(5):682-6. [Medline: 1063970] [doi: 10.1016/0030-4220(76)90325-X]

67. Wang TM, Shih C, Liu JC, Kuo KJ. A clinical and anatomical study of the location of the mental foramen in adult Chinese mandibles. Acta Anat (Basel). 1986;126(1):29-33. [Medline: 3739600] [doi: 10.1159/000146182]

68. Shankland WE 2nd. The position of the mental foramen in Asian Indians. J Oral Implantol. 1994;20(2):118-23. [Medline: 7869414]

69. al Jasser NM, Nwoku AL. Radiographic study of the mental foramen in a selected Saudi population. Dentomaxillofac Radiol. 1998 Nov;27(6):341-3. [Medline: 10895632] [doi: 10.1038/sj.dmfr.4600388]

70. Ngeow WC, YuzawatiY. The location of the mental foramen in a selected Malay population. J Oral Sci. 2003 Sep;45(3):171-5. [Medline: 14650583 ]

71. Mraiwa N, Jacobs R, Moerman P, Lambrichts I, van Steenberghe D, Quirynen M. Presence and course of the incisive canal in the human mandibular interforaminal region: two-dimensional imaging versus anatomical observations. Surg Radiol Anat. 2003 Nov-Dec;25(5-6):416-23. [Medline: 13680184] [doi: 10.1007/s00276-003-0152-8]

72. Cranin AN. Implant surgery: the management of soft tissues. J Oral Implantol. 2002;28(5):230-7. [Medline: 12498472] [doi: 10.1563/1548-1336(2002)028<0230:ISTMOS>2.3.CO;2]

73. Solar P, Frey G, Ulm C, Gruber H, Matejka M. A Classification of the intraosseous paths of the mental nerve. Int. J. oral max. Fac. Implant. 1994;9(3): 339-44.

74. Kieser J, Kuzmanovic D, Payne A, Dennison J, Herbison P. Patterns of emergence of the human mental nerve. Arch Oral Biol. 2002 Oct;47(10):743-7. [Medline: 12356506] [doi: 10.1016/S0003-9969(02)00067-5]

75. Sawyer DR, Kiely ML, Pyle MA. The frequency of accessory mental foramina in four ethnic groups. Arch Oral Biol. 1998 May;43(5):417-20. [Medline: 9681117] [doi: 10.1016/S0003-9969(98)00012-0]

76. Katakami K, Mishima A, Shiozaki K, Shimoda S, Hamada Y, Kobayashi K. Characteristics of accessory mental foramina observed on limited cone-beam computed tomography images. J Endod. 2008 Dec;34(12):1441-5. [Medline: 19026870] [doi: $10.1016 /$ j.joen.2008.08.033]

77. Naitoh M, Hiraiwa Y, Aimiya H, Gotoh K, Ariji E. Accessory mental foramen assessment using cone-beam computed tomography. Oral Surg Oral Med Oral Pathol Oral Radiol Endod. 2009 Feb;107(2):289-94. [Medline: 19071039] [doi: $10.1016 /$ j.tripleo.2008.09.010] 
78. Morrison A, Chiarot M, Kirby S. Mental nerve function after inferior alveolar nerve transposition for placement of dental implants. J Can Dent Assoc. 2002 Jan;68(1):46-50. [Medline: 11844418] [FREE Full Text]

79. Babbush CA. Transpositioning and repositioning the inferior alveolar and mental nerves in conjunction with endosteal implant reconstruction. Periodontol 2000. 1998 Jun;17:183-90. [Medline: 10337324] [doi: 10.1111/j.1600-0757.1998.tb00134.x]

80. Hori M, Sato T, Kaneko K, Okaue M, Matsumoto M, Sato H, Tanaka H. Neurosensory function and implant survival rate following implant placement with nerve transpositioning: a case study. J Oral Sci. 2001 Jun;43(2):139-44. [Medline: 11515599]

81. Nocini PF, De Santis D, Fracasso E, Zanette G. Clinical and electrophysiological assessment of inferior alveolar nerve function after lateral nerve transposition. Clin Oral Implants Res. 1999 Apr;10(2):120-30. [Medline: 10219131] [doi: 10.1034/j.1600-0501.1999.100206.x]

82. Ellies LG, Smiler DG, Quadland MW, Babbush CA, Krogh PH, Shepherd NJ. Inferior alveolar nerve repositioning: is there cause for concern? Dent Implantol Update. 1995 May;6(5):37-9. [Medline: 9525145]

83. Phillips JL, Weller RN, Kulild JC. The mental foramen: 1. Size, orientation, and positional relationship to the mandibular second premolar. J Endod. 1990 May;16(5):221-3. [Medline: 2074415] [doi: 10.1016/S0099-2399(06)81674-2]

84. Moiseiwitsch JR. Avoiding the mental foramen during periapical surgery. J Endod. 1995 Jun;21(6):340-2. [Medline: 7673846] [doi: 10.1016/S0099-2399(06)81014-9]

85. Jacobs R, Mraiwa N, Van Steenberghe D, Sanderink G, Quirynen M. Appearance of the mandibular incisive canal on panoramic radiographs. Surg Radiol Anat. 2004 Aug;26(4):329-33. [Medline: 15197490] [doi: 10.1007/s00276-004-0242-2]

86. Sonick M, Abrahams J, Faiella RA. A comparison of the accuracy of periapical, panoramic, and computerized tomographic radiographs in locating the mandibular canal. Int J Oral Maxillofac Implants 1994;9:455-460.

87. Lindh C, Petersson A. Radiologic examination for location of the mandibular canal: a comparison between panoramic radiography and conventional tomography. Int J Oral Maxillofac Implants. 1989 Fall;4(3):249-53. [Medline: 2639123]

88. Bou Serhal C, Jacobs R, Flygare L, Quirynen M, van Steenberghe D. Perioperative validation of localization of the mental foramen. Dentomaxillofac Radiol 2002;31:39-43. [Medline: 11803387] [doi: 10.1038/sj.dmfr.4600662]

89. Ekestubbe A, Gröndahl K, Gröndahl HG. The use of tomography for dental implant planning. Dentomaxillofac Radiol. 1997 Jul;26(4):206-13. [Medline: 9442610] [doi: 10.1038/sj.dmfr.4600249]

90. Sakakura CE, Morais JA, Loffredo LC, Scaf G. A survey of radiographic prescription in dental implant assessment. Dentomaxillofac Radiol. 2003 Nov;32(6):397-400. [Medline: 15070843] [doi: 10.1259/dmfr/20681066]

91. Loubele M, Guerrero ME, Jacobs R, Suetens P, van Steenberghe D. A comparison of jaw dimensional and quality assessments of bone characteristics with cone-beam CT, spiral tomography, and multi-slice spiral CT. Int J Oral Maxillofac Implants. 2007 May-Jun;22(3):446-54. [Medline: 17622012]

92. Arai Y, Tammisalo E, Iwai K, Hashimoto K, Shinoda K. Development of a compact computed tomographic apparatus for dental use. Dentomaxillofac Radiol. 1999 Jul;28(4):245-8. [Medline: 10455389] [doi: 10.1038/sj.dmfr.4600448]

93. Mozzo P, Procacci C, Tacconi A, Martini PT, Andreis IA. A new volumetric CT machine for dental imaging based on the cone-beam technique: preliminary results. Eur Radiol. 1998;8(9):1558-64. [Medline: 9866761] [doi: $10.1007 / \mathrm{s} 003300050586$ ]

94. JalboutZ, Tabourian G. Glossary of Implant Dentistry. Upper Montclair, NJ: International Congress of Oral Implantologists; 2004:16.

95. Arzouman MJ, Otis L, Kipnis V, Levine D. Observations of the anterior loop of the inferior alveolar canal. Int J Oral Maxillofac Implants. 1993;8(3):295-300. [Medline: $\underline{8225464]}$

96. Bavitz JB, Harn SD, Hansen CA, Lang M. An anatomical study of mental neurovascular bundle-implant relationships. Int J Oral Maxillofac Implants. 1993;8(5):563-7. [Medline: 8112797]

97. Misch CE. Root form surgery in the edentulous mandible: Stage I implant insertion. In: Misch CE, editors. Implant Dentistry, 2nd ed. St. Louis: The CV Mosby Company; 1999. p. 347-370.

98. Kuzmanovic DV, Payne AG, Kieser JA, Dias GJ. Anterior loop of the mental nerve: a morphological and radiographic study. Clin Oral Implants Res. 2003 Aug;14(4):464-71. [Medline: 12869009] [doi: 10.1034/j.1600-0501.2003.00869.x]

99. Rosenquist B. Is there an anterior loop of the inferior alveolar nerve? Int J Periodontics Restorative Dent. 1996 Feb;16(1):40-5. [Medline: 8631609]

100. Mardinger O, Chaushu G, Arensburg B, Taicher S, Kaffe I. Anterior loop of the mental canal: an anatomical-radiologic study. Implant Dent. 2000;9(2):120-5. [Medline: 11307391] [doi: 10.1097/00008505-200009020-00003]

101. Misch CE, Crawford EA. Predictable mandibular nerve location - a clinical zone of safety. Int J Oral Implantol. 1990;7(1):37-40. [Medline: 2103117]

102.Jacobs R, Mraiwa N, vanSteenberghe D, Gijbels F, Quirynen M. Appearance, location, course, and morphology of the mandibular incisive canal: an assessment on spiral CT scan. Dentomaxillofac Radiol. 2002 Sep;31(5):322-7. [Medline: 12203132] [doi: 10.1038/sj.dmfr.4600719]

103. Rothman SLG. Dental Applications of Computerized Tomography. Chicago: Quintessence; 1998:42-45. 
104.Uchida Y, Noguchi N, Goto M, Yamashita Y, Hanihara T, Takamori H, Sato I, Kawai T, Yosue T. Measurement of anterior loop length for the mandibular canal and diameter of the mandibular incisive canal to avoid nerve damage when installing endosseous implants in the interforaminal region: a second attempt introducing cone beam computed tomography. J Oral Maxillofac Surg. 2009 Apr;67(4):744-50. [Medline: 19304029] [doi: 10.1016/j.joms.2008.05.352]

105. Obradovic O, Todorovic L, Pesic V, Pejkovic B, Vitanovic V. Morphometric analysis of mandibular canal: clinical aspects. Bull Group Int Rech Sci Stomatol Odontol. 1993 Jul-Sep;36(3-4):109-13. [Medline: 8219689]

106.De Andrade E, Otomo-Corgel J, Pucher J, Ranganath KA, St George N Jr. The intraosseous course of the mandibular incisive nerve in the mandibular symphysis. Int J Periodontics Restorative Dent. 2001 Dec;21(6):591-7. [Medline: 11794570]

107. Romanos GE, Greenstein G. The incisive canal. Considerations during implant placement: case report and literature review. Int J Oral Maxillofac Implants. 2009 Jul-Aug;24(4):740-5. [Medline: 19885417]

108. Kohavi D, Bar-Ziv J. Atypical incisive nerve: clinical report. Implant Dent. 1996 Winter;5(4):281-3. [Medline: 9206396] [doi: 10.1097/00008505-199600540-00007]

109. Wismeijer D, van Waas MA, Vermeeren JI, Kalk W. Patients' perception of sensory disturbances of the mental nerve before and after implant surgery: a prospective study of 110 patients. Br J Oral Maxillofac Surg. 1997 Aug;35(4):254-9. [Medline: 9291263] [doi: 10.1016/S0266-4356(97)90043-7]

110. Pires CA, Bissada NF, Becker JJ, Kanawati A, Landers MA. Mandibular Incisive Canal: Cone Beam Computed Tomography. Clin Implant Dent Relat Res. 2009 Aug 6. [Epub ahead of print] [Medline: 19673957]

111. Tyndall DA, Brooks SL. Selection criteria for dental implant site imaging: a position paper of the American Academy of Oral and Maxillofacial radiology. Oral Surg Oral Med Oral Pathol Oral Radiol Endod. 2000 May;89(5):630-7. [Medline: 10807723] [doi: 10.1067/moe.2000.106336]

\section{To cite this article:}

Juodzbalys G, Wang HL. Guidelines for the Identification of the Mandibular Vital Structures: Practical Clinical Applications of Anatomy and Radiological Examination Methods.

J Oral Maxillofac Res 2010;1(2):e1

URL: http://www.ejomr.org/JOMR/archives/2010/2/e1/e1ht.pdf

doi:10.5037/jomr.2010.1201

Copyright (C) Juodzbalys G, Wang HL. Accepted for publication in the JOURNAL OF ORAL \& MAXILLOFACIAL RESEARCH (http://www.ejomr.org), 17 March 2010.

This is an open-access article, first published in the JOURNAL OF ORAL \& MAXILLOFACIAL RESEARCH, distributed under the terms of the Creative Commons Attribution-Noncommercial-No Derivative Works 3.0 Unported License, which permits unrestricted non-commercial use, distribution, and reproduction in any medium, provided the original work and is properly cited. The copyright, license information and link to the original publication on (http://www.ejomr.org) must be included. 